\title{
Section 18 valuations: Wisdom or witchcraft?
}

Received (in revised form): 14th October, 2008

\begin{abstract}
David Gilbert BSc (Hons) Dip Arb FRICS FCIArb IRRV
is a Fellow of the Royal Institution of Chartered Surveyors (RICS) and of the Chartered Institute of Arbitrators (CIArb). $\mathrm{He}$ is also a member of the Institute of Revenues Rating and Valuation. He commenced practice with the Inland Revenue in 1978, moving in to private practice in 1988. He is a Director of Lambert Smith Hampton, where he has headed Valuation and Lease Advisory for over three years. David deals with a wide variety of work associated with the valuation of commercial property, and the provision of advice on landlord and tenant issues. This is undertaken on behalf of financial institutions, public and private clients, and charities. A substantial part of his time is involved with dispute resolution. In 1993, he was one of the first to be awarded a Diploma in Arbitration by The College of Estate Management. He is a Chartered Arbitrator and appears on both CIArb and RICS Presidents' Arbitration Panels.
\end{abstract}

Correspondence: David Gilbert, Midland House, West Way, Botley, Oxford OX2 OPH, UK; Tel: +44 1865200244 ; Fax: +44 1865204822

\begin{abstract}
This paper seeks to investigate the impact of Section 18 of the Landlord and Tenant Act 1927 in settlement of dilapidation disputes. This is seen as a developing issue, in current economic conditions. The paper looks at the two limbs of Section 18, and offers practical advice to valuers on preparation of Section 18 valuations. By close analysis of the second limb followed by the first limb, the impact of the terms of the Act upon diminution in value used as a defence by tenants against landlord claims under dilapidations can be identified. This paper recognises that preparation of Section 18 valuations is a practical rather than a theoretical exercise and seeks to offer practical advice based upon the author's extensive experience of undertaking such work. The work is, however, mindful of the potential for litigation following such disputes and the role of the valuer in such an event.
\end{abstract}

Journal of Building Appraisal (2009) 4, 169-180. doi:10.1057/jba.2008.38

\section{Keywords:}

dilapidation, diminution, valuer, building surveyor, disrepair, schedule of dilapidations, Section 18 valuation

\section{INTRODUCTION}

There are probably few more emotive subjects between landlord and tenant than the issue of dilapidations at the end of a lease. It is also perhaps something which we will see becoming more of an issue if the market proves to be as difficult over the next 12 months or more as it has been over the last 12 months. With tenants facing difficult times financially and concentrating on keeping the business afloat, the last likely thing on their mind is the repair of the landlord's building. This is an area in which there appears to be more argument developing, possibly fuelled by the high prices that have been paid for investment property. Understandably, landlords are seeking to extract every last penny out of the property in justification of the high prices and low yields that they have paid over the last few years. Conversely, tenants are trying to keep costs to a minimum.

This paper is not intended to be a treatise on the law to any great extent, but merely a practical look at the underlying valuation issues that arise under Section 18 of the Landlord and Tenant Act 1927 ('the Act'). 
It has been noted that this is an area that is not particularly well understood by building surveyors or solicitors, who tend to generalise in terms of Section 18 matters rather than look at each case on its merits. One must always be at pains to point out that no two dilapidations cases can be compared and circumstances that may arise in one cannot necessarily be applied to the other. The author therefore intends to set out what are seen as the ground rules for assessing the diminution in value and thereafter to consider a number of practical matters that may apply in individual cases. These will be by no means exhaustive or exclusive but the author hopes to show how individual circumstances can vary in each case.

\title{
GENERAL MATTERS
}

Before considering specific matters that are likely to arise, it is important to review the general background and overriding criteria in Section 18 cases. No apology is made for setting this section of the Act out, in full. This paper separates what are commonly described as first and second limbs, although they encompass one section of the Act, for reasons that will become clear later. The provisions are as follows:

\section{First Limb}

'18(1) Damages for a breach of a covenant or agreement to keep or put premises in repair during the currency of a lease, or to leave or put premises in repair at the termination of a lease, whether such covenant or agreement is expressed or implied, and whether general or specific, shall in no case exceed the amount (if any) by which the value of the reversion (whether immediate or not) in the premises is diminished owing to the breach of such covenant or agreement as aforesaid;'

\section{Second Limb}

\begin{abstract}
'and in particular no damage shall be recovered for a breach of any such covenant or agreement to leave or put premises in repair at the termination of a lease, if it is shown that the premises, in whatever state of repair they might be, would at or shortly after the termination of the tenancy have been or be pulled down, or such structural alterations made therein as would render valueless the repairs covered by the covenant or agreement'. (Bold type denotes the author's emphasis)
\end{abstract}

It is therefore clear that this work not only looks at diminution in reversionary value, but also at the effect of any future actions by the landlord. The exercise for the valuer is not just an academic valuation one, but also requires a very practical look at the future of the property.

\section{WHEN IS A SECTION 18 VALUATION REQUIRED?}

Given that Section 18 valuations can be relatively costly to produce, in the author's experience they are usually avoided until late in the proceedings and hence the valuer is called in almost at the 11th hour. This can be considered to be a mistake for reasons that will be explained later. There is little direct assistance in answering this question in the RICS Guidance Note on Dilapidations. It could be argued that it infers that a judgment will have to be made at the claim stage as to whether a diminution valuation should be prepared insofar as it impacts on the claim. In many simple claims, however, it will be of no significance, the claim simply being the cost of the work. At the other extreme, it may be obvious that a diminution valuation is likely to produce a significantly different answer to that of assessing the cost of the work, in which case it may be suggested that one should be appended to the claim, otherwise the surveyor preparing it cannot sign the endorsement as to reasonableness. ${ }^{1}$ It is for the tenant to plead the diminution point as a defence if it is thought that it will impact on the landlord's loss. 
The Property Litigation Association has produced a revised pre-action protocol (May 2008), which is used in dilapidations cases. This is slightly more helpful and gives the following guidance: ${ }^{2}$

- If the landlord has carried out the work he considers should have been done, he is not usually required to provide a formal valuation ... the landlord should provide a valuation where it is reasonable to do. The same advice is given if the landlord has carried out only some of the work required.

- If the landlord has not carried out the work but intends to do so, he should provide a valuation, unless it would be reasonable not to.

- If the landlord does not intend to do the work, he should provide a valuation, unless it would be reasonable not to.

- If the tenant relies on a defence based on diminution, he must state his case for doing so and provide a diminution valuation to the landlord.

This brief summary leaves a lot to the question of reasonableness. In the author's experience, it is a very nebulous concept, and probably best left to be answered by property litigators. The courts seem to have been marginally more helpful and have decided that while it can be inferred from circumstantial evidence that there has been a diminution in the value of the reversion, a landlord is foolish not to adduce expert evidence to this effect. ${ }^{3}$ Diminution may be argued without adducing expert evidence; however, the author believes this would be a very risky and foolhardy action.

In practical terms, both of these documents point to the diminution valuation actually being prepared relatively late in the proceedings. While the formal valuation might be produced at this stage, it is the author's firm belief that advice from the valuer should be taken significantly earlier. It is impossible to see how a landlord can assess the outcome of serving a schedule, or how the tenant can assess its likely liabilities, without the advice of the valuer at an early stage. It is very likely that there will be significant matters for the building surveyors to include in the schedule, which, by no stretch of the imagination, will have an effect on value. Failure to consult a valuer early in the process may result in an entirely inappropriate schedule being served, or claim being made, at significant time and cost, and, ultimately, great embarrassment to the parties.

As an example, the author was asked to produce a Section 18 valuation for a client, against a subtenant, in relation to his ten-year reversionary interest in a very substantial old warehouse. The dilapidations schedule included almost $£ 100,000$ for redecorating steel work, on which there had been at least 12 months' argument before a valuer became involved. The author was left to explain to the landlord that he would have to remove this amount from his claim under the first limb of Section 18. Understandably, the landlord was not happy about the time and expense that had been spent in arguing an academic point.

It is the author's firm belief that the valuer's advice should be obtained at as early a stage as possible in the proceedings, even if only to comment on valuation matters, if not to produce a valuation. Setting the question of when a valuer should be called in to one side the author next considers the practical approach to diminution.

\section{SECOND LIMB}

Perhaps perversely, this paper will address the second limb first, as it is impossible to assess diminution, if any, under the first limb before considering it. 
This limb is often overlooked, except in circumstances where it is clear that the property will be redeveloped. While clearly it is designed to prevent a landlord from recovering damages, in circumstances where it is likely that the demise will be redeveloped (and the repairs rendered valueless), it is important that thought is not restricted solely to wholesale redevelopment. The valuer should consider carefully the likely future of the building, even if it is to be retained. While planning enquiries will clearly be necessary, equally so will a thorough consideration and investigation of the landlord's intention for the building. The Dilapidations Guidance Note recommends that a surveyor asks the landlord for his intentions for the property in writing before effectively signing off the dilapidations schedule, reflecting those intentions. ${ }^{4}$

In general, where future development is very likely, it is rarely difficult to convince landlords that the second limb of Section 18 operates, and that no diminution in value would result. There are, however, various halfway houses in which the landlord may be intending to carry out some form of redevelopment, but certain parts of the demise or its structure will be retained and hence a contingent repair liability may still remain.

Take, for example, the refurbishment of a town centre shop, including conversion of the upper floors for residential purposes. The tenant may still be required to carry out work on the external envelope or services, insofar as they are not part of the re-development plans. Conversely, in circumstances where work will be required on any of these items, perhaps to comply with requirements of the market, or even just of Building Regulations, it may still be possible to argue that the repair obligation will be overtaken by the landlord's work in due course.

The second limb may also come to the tenants rescue in a number of other circumstances. There are many instances where work will be required by the landlord on the demise, which goes beyond repair, merely in order to relet or resell at the end of the lease. Taking, say, a 1960s office building as an example, there are numerous areas where damages for disrepair may be curtailed by the second limb. Simple examples might be as follows:

- Asbestos has been discovered within the structure and its removal is required before the commencement of refurbishment work, necessitating the removal of ceilings, floors or services.

- The market may require that in order to relet the building the landlord has to carry out modernisation work such as the installation of suspended ceilings or raised floors.

- As part of the refurbishment, it will be necessary to replace all the windows with modern sealed unit double glazing in order to comply with Building Regulations. Increasing the energy efficiency of buildings is becoming a hot topic and ultimately even the insulation of a building may render repair work valueless.

- An old building without disabled WC or lift accommodation may require their installation to comply with the Disability Discrimination Act 1995.

- External work may be required to provide adequate parking or to reconfigure landscaping or grounds.

In all of these circumstances, the need for the landlord to carry out the work simply to relet the building may, in the author's view, provide a defence to the tenant under the second limb of Section 18, negating any diminution in value in relation to some or all of the repairs. It is, though, worth warning of circumstances where any renewal is a factor of the disrepair, that is, where the only repair is one of replacement, rather than encompassing some grand plans for refurbishment by the landlord. 
It can therefore be concluded that careful thought needs to be given to the likely future of the building to identify those areas where repairs may be rendered valueless by future work before the valuation process begins.

Much of what has been said may depend on proving the landlord's intentions for the building. Rarely has this information been volunteered. The Guidance Note now recommends that the landlord surveyor asks for and keeps a written record of future intent from the landlord client. ${ }^{5}$ If not provided to the tenant's surveyor, it must be asked for value's should also ask for solicitors to arrange disclosure at an early stage. It is amazing what interesting facts arise out of Board Minutes, Asset Valuations or Marketing Reports. Any well-versed property litigator will be wise to this but solicitors unfamiliar with dilapidations cases may not.

\section{EMPTY PROPERTY RATES}

Empty property rates are a developing area that may have an impact on Section 18 insofar as the second limb is concerned. The government changed the empty property rate provisions with effect from 1st April, $2008^{6}$ to the extent that the reliefs available to commercial and industrial occupiers no longer apply. This is having a massive impact on the commercial property market, with landlords of empty premises facing huge bills on an annual basis. Many older valuers still remember these provisions under previous legislation, when landlords tried to find ways of rendering a building incapable of beneficial occupation and hence having it removed from the Rating List. Although originally the government had intended to introduce accompanying legislation in relation to anti-avoidance measures, the Secretary of State has announced that the government will not do so immediately, but that it will first monitor the situation. ${ }^{7}$

In circumstances where landlords are faced with particularly old and unlettable buildings (for example, old mill buildings or low eaves height north-light sheds), they may look to find ways of removing rates liability. It is possible that there may be a return to the days when roofs were removed from buildings simply to have them taken out of the Rating List. From a Section 18 point of view, this would render valueless repair work that would be related certainly to the roof and possibly a good deal of the interior of the building and services that would then be exposed to the elements. If so, this may become a developing area and therefore anyone looking to carry out Section 18 valuations should be trying to establish whether the landlord is going to try and take any anti-avoidance measures that might impact the issue of dilapidations.

This concludes the consideration of the second limb and a suggested approach at this point would be to obtain an electronic copy of the schedule and add a 'Yes or No' column to gauge whether the second limb applies to the repair item listed. After this, one can return to the first limb and the calculation of the diminution in value, if any.

\section{FIRST LIMB}

It is worth remembering that the Act is quite clear and refers to the consequences of failure to '...leave or put the premises in repair...'

This paper does not intend to become embroiled in discussions as to what constitutes disrepair, and therefore assumes that whether acting for landlord or tenant, a valuer will be guided by the respective building surveyor on such matters. All too often it happens that there is substantial dispute as to (a) what constitutes disrepair and (b) the method by which repairs, satisfactory for the purposes of the repairing liability under the lease, can be achieved. It can be suggested to valuers that they do not become 
Table I: Valuation example of an industrial building - repair cost $€ 150,000$

\begin{tabular}{|c|c|c|c|}
\hline \multicolumn{4}{|l|}{ Value in repair } \\
\hline Rental value & $E 100,000$ & & \\
\hline \multicolumn{4}{|l|}{ Marketing period nine months } \\
\hline \multicolumn{4}{|l|}{ Rent free period three months } \\
\hline \multicolumn{4}{|l|}{ Perpetuity deferred } \\
\hline 12 months at $8 \%$ & 11.574 & $£ I, I 57,400$ & \\
\hline Deduct purchasers costs $5.75 \%$ & & $£ 66,551$ & $£ 1,090,849$ \\
\hline \multicolumn{4}{|l|}{ Value out of repair } \\
\hline Rental value & $£ 100,000$ & & \\
\hline \multicolumn{4}{|l|}{ Void for works six months } \\
\hline \multicolumn{4}{|l|}{ Marketing period nine months } \\
\hline \multicolumn{4}{|l|}{ Rent free period three months } \\
\hline \multicolumn{4}{|l|}{ Perpetuity deferred } \\
\hline 18 months at $8.25 \%$ & 11.137 & $€ I, I \mid 3,700$ & \\
\hline \multirow[t]{2}{*}{ Deduct cost of repairs } & & $£ 150,000$ & \\
\hline & & & $£ 963,700$ \\
\hline Deduct purchasers costs $5.75 \%$ & & $£ 55,4 / 3$ & $£ 908,287$ \\
\hline Diminution in value & & & $€ \mid 82,562$ \\
\hline
\end{tabular}

embroiled in such things and leave the building surveyors to deal with them as part of their remit.

On reading any dilapidations textbook on the valuation process, there will be direction to a 'Before and After Valuation', the landlord's loss being quantified as the difference between the 'Value in Repair' and the 'Value Out of Repair'. The actual valuation will depend on the circumstances and the market for the asset. This approach is also referred to in the Dilapidations Guidance Note. ${ }^{8}$ It is necessary to look very carefully at the class of purchaser that will produce the best price and how that purchaser would consider the disrepair for the purpose of their valuation of the property. The valuation approach will vary for different classes of purchaser. In providing a simple valuation example, it is assumed that this is an investment valuation, and therefore an industrial building has been chosen for ease of reference. A typical textbook example is shown in Table 1. In this example, the cost of work is less than the diminution, and hence Section 18 is no defence to the claim.

If producing a valuation in this manner were that simple, it would not require a valuer; however, it is never this simple. Too often, in the author's experience, valuers give insufficient thought to the component parts of the valuation, relying on textbook approaches.

\section{RENT AND RETURNS}

It is the author's firm belief that where the measure of loss requires the deduction of the cost of repair, the rent in both cases should generally be the same. There have been valuations in which the valuer has endeavoured to attach a reduced rent to a building in disrepair. The author strongly disagrees with this approach unless comparable evidence is available, as the calculation of the rent of such a building can only be theoretical. It is rarely possible to calculate the rent of a building with a defective roof or assess if say $£ 0.35 \mathrm{ft}^{2}$ is sufficient deduction for a building in disrepair compared with one in repair. It could just as easily be $£ 0.30$ or $£ 0.40$. In the author's experience, this approach tends to be based on some form of amortisation of the repair cost; hence, why should a valuer not just deduct the cost of repair in the first place? When going down the line of adopting a different rent in the 'Out of Repair' scenario, please note that it is critical that there is available evidence. If this is not available, it is the author's view that this approach is unsustainable. 
The issue of return can also stray into the theoretical. There are examples of the yield in the 'Out of Repair' valuation being higher than the 'In Repair' valuation. This is theoretically possible because the investor carries a greater risk. In practice though, this risk is usually picked up in the repair costs. If the landlord has received quotes or has carried out the work then there should be no extra risk. If he has not, then the costed schedule should be inspected closely, as it may include provisional sums or contingency percentages. This increase of the yield is therefore double counting where allowance has been made for contingencies, etc.

\section{REPAIR AND REINSTATEMENT}

A big mistake, whether acting for landlord or tenant, is to simply accept the schedule of dilapidations as constituting matters of repair that will have an effect on value. Too many valuers just dump the whole repair cost into the calculation. If you have followed the advice offered in this paper in considering the 'Second Limb', those matters that cannot attract damages will have been identified and consequently will have been removed for valuation purposes.

Most schedules of dilapidations include everything as well as the kitchen sink and therefore incorporate matters of repair, redecoration, cleaning, reinstatement and the like. Section 18 concerns itself only with matters of 'repair' and consequently many of the items referred to in the schedule do not fall within the province of the Section 18 valuation. For example, it was for a long time considered that decoration was not repair but this matter was recently resolved in the case of Ferguson Latimer and Another $v$ Carney ${ }^{9}$ and therefore should now generally be regarded as part of the items of disrepair when included in the schedule. Other items such as reinstatement and cleaning are not repairs save insofar as failure to carry them out may of itself constitute disrepair. The best example would be, say, the removal of partitions that in themselves do not constitute repair, being reinstatement, whereas the holes that may have been left in the walls or floor where they were secured most certainly constitute disrepair.

Furthermore, automatic reinstatement cannot be assumed. A valuer should be able to identify items that might actually add to value if left in situ; hence their removal will actually diminish value, not their apparent state of repair. On discovery that the landlord is not mitigating his loss by leaving these items in place, a valuer should be alert to any repair costs that might attach to them if left in situ. The building surveyors may not have picked this up in the schedule and it may be sought as a cost.

While reinstatement items may not form part of the definition of repair and therefore do not strictly fall within a Section 18 valuation, it may be that diminution in value is the correct way of assessing any losses that the landlord would face by virtue of the breach of, say, a reinstatement provision. It is now generally accepted that a valuation should cover all items that have the effect of diminishing value, not merely those that simply fall under the banner of Section 18. This approach is encouraged in the Protocol. ${ }^{10}$ For practical purposes, it is wise to refer to them separately in any consideration of losses or valuation.

From a practical point of view, the next step for any valuer is to scrutinise the repair schedule and establish within which class each item listed falls. The author generally adopts the following: repair, redecoration, cleaning, reinstatement and other matters, as it is relatively rare that this will be done by the building surveyors. The easiest way of dealing with it is to work with the electronic copy of the schedule and add additional 
columns denoting each of these categories. The final column would record items that on a market assessment are considered to have the effect of diminishing value. This allows the schedule to identify those works that will affect the value in the eyes of the purchaser and those that will not. Consequentially, it becomes easy to total up the cost of work that is value effective.

In dealing with each item in this way, a valuer should ask the simple question, 'Do I as a valuer believe this item is likely to diminish value in the eyes of the class of purchaser I have identified?' To answer this question, the purchaser must be identified. This is because an owner occupier may be less concerned about the overall image of a building than an investor who has to attract a tenant.

For example, in the case of a large old warehouse does it really matter to the prospective occupier, whether owner or tenant, that the walls are not painted the unmarked brilliant white of a Chelsea show home? The fact that the roof leaks, or the loading doors will not close on the warehouse, may be important, but the fact that there are fixing holes left in the wall of the WCs from where the condom machine was removed is unlikely to be of any great importance.

While in general it may be reasonable to strike out all minor matters, it is equally important to stand back and decide whether they may cumulatively reduce value even if they do not do so individually. It is also important to consider whether, if they do not affect value, they might extend the marketing period, and hence increase losses in respect of, say, an increased rental void.

Having been through the schedule in this way, the next question to be asked concerns the extent to which the cost of repair of each item is the correct angle from which to approach the valuation.

In a major case where costs run in to many hundreds of thousands of pounds, it may be that the prospective purchaser will simply make a deduction from the price to reflect the cost of the works possibly with an element of contingency and other out of pocket expenses. Alternatively in a very minor case the loss might be reflected in a short rent free period, to secure an incoming tenant, and not always equate to the cost of the works. This is one very major reason why the valuer must be familiar with the market and carry out a thorough market analysis prior to establishing the extent to which, the disrepair affects value.

Having looked specifically at repairs, the author now turns to ancillary losses.

\section{LOSS OF RENT}

It is a generally accepted head of claim that a landlord may incur a loss of rent during the period in which the repair work is carried out. The author's general experience is that a simple estimate of " $\mathrm{X}$ " months is imported into the valuation merely by reason of the period of time it will take to have repair work carried out. In itself, this is a logical exercise, but in practical terms the valuer needs to take into account the effect that the disrepair may have on marketing. In some instances, the repair work can be carried out during the normal marketing period and will have no effect on extending it. In the author's experience, this is frequently the case with industrial property, although it may be less so in the case of offices. In the case of many retail properties, prospective occupiers will generally regard them as a shell and will consequently expect some stripping out and refitting. They may expect to change shop fronts and reconfigure services. In such circumstances, the likelihood of all repair work extending the marketing period is debatable and only where it does so can this head of claim reasonably be supported. The question is simply whether the disrepair actually increases 
the marketing period. If it does not, this is not a valid head of claim and should not be a constituent part of the valuation.

\section{RATES AND SERVICE CHARGE}

As with rental voids, periods when a building is empty and work has to be carried out before it can be re-occupied or sold can lead to irrecoverable losses examples as losses or service charges or rates. It is reasonable for a valuer to factor these into a diminution calculation, but seldom do they seem to appear. As cited previously, empty property rates have become a very serious problem from 1st April, 2008 and need to be considered. It is equally worth considering whether the work is extensive or incorporates an element of redevelopment. If so, the landlord should mitigate his losses and take the building out of the Rating List. It should not be forgotten that some classes of property such as Listed Buildings are exempt from empty property rates and that this does not therefore constitute a head of claim for such buildings.

\section{INTEREST CHARGES AND FEES}

In the case of major repair bills, particularly where the purchaser is likely to be a developer, it is not unreasonable to consider the cost of financing the repairs. The professional team fees for planning and supervision should also be added to the cost of repair. These are frequently added as a lump sum by the building surveyor. Given that a number of items may have been removed from the schedule, from a valuation perspective these require recalculation, usually as a percentage of cost.

\section{REVISED VALUATION}

Having thought about all of these additional matters and discounted a number of the repair/reinstatement items scheduled, the valuation may now change, as shown in Table 2. Clearly, in this case the diminution is less than the cost of the work and comes to the tenant's defence.

Table 2: Revised valuation of example in Table I — repair cost reduced by one-third

\begin{tabular}{|c|c|c|c|}
\hline \multicolumn{4}{|l|}{ Value in repair } \\
\hline Rental value & $£ 100,000$ & & \\
\hline \multicolumn{4}{|l|}{ Marketing period nine months } \\
\hline \multicolumn{4}{|l|}{ Rent free period three months } \\
\hline \multicolumn{4}{|l|}{ Perpetuity deferred } \\
\hline 12 months at $8 \%$ & II.574 & $€ I, 157,400$ & \\
\hline Deduct purchasers costs $5.75 \%$ & & $(£ 66,55 l)$ & $£ 1,090,849$ \\
\hline \multicolumn{4}{|l|}{ Value out of repair } \\
\hline Rental value & $£ 100,000$ & & \\
\hline \multicolumn{4}{|l|}{ Marketing period nine months } \\
\hline \multicolumn{4}{|l|}{ Perpetuity deferred } \\
\hline 12 months at $8 \%$ & I I.574 & $£ I, \mid 57,400$ & \\
\hline Deduct cost of repairs & & $(£ \mid 00,000)$ & \\
\hline Deduct contingencies $5 \%$ & & $(£ 5,000)$ & \\
\hline Deduct fees at $12.5 \%$ & & $( \pm 13,125)$ & \\
\hline Interest charges half cost for three months & & $(£ 2,067)$ & \\
\hline & & & \\
\hline Deduct purchasers costs $5.75 \%$ & & $£ 59,639$ & $£ 977,569$ \\
\hline Diminution in value & & & $E I \mid 3,280$ \\
\hline
\end{tabular}




\section{NEGATIVE VALUATION}

When valuing leasehold interests and in difficult markets, it is not uncommon to have to offer reverse premiums to attract a purchaser. Effectively, the value of the property is negative. In theory, this could arise in the case of freehold premises but is less likely than when valuing a short reversionary leasehold interest. Notwithstanding that a negative value is likely to arise, the principles of the valuation are no different either 'In Repair' or 'Out of Repair'. The end result is simply a larger negative value in the 'Out of Repair' scenario. This still results in a diminution in the value of the landlord's interest on account of that greater negative value. Such loss is recognised and should be treated in the same way as a loss where the values are positive. ${ }^{11}$

A word of advice is appropriate here, that is, to be careful to compare repair liabilities under head-lease and sub-lease. If they are different, there is no guarantee that whatever dilapidations settlement has been reached, or is believed to apply under the headlease automatically cascades down to the underlease. This matter arose in a relatively complicated recent case that is worthy of consideration if you are faced with this problem. ${ }^{12}$

\section{BETTERMENT}

The author also recommends that valuers keep in mind the possibility of 'Betterment' arising out of the landlord's works. That is, an increase in the value of the landlord's reversionary interest arising out of more than simply the obligation to comply with the lease terms.

It is unlikely that this issue will arise in relation to items of disrepair. It is more likely to arise where diminution arises out of the breach of another lease term, such as reinstatement. The author has only once faced this problem, but in circumstances where betterment had the potential to have a very significant impact on the landlord's claim. Failure by either the landlord or the tenant's valuer to address this issue could at the least be embarrassing and at worst result in a potential negligence claim if the proceedings are settled on the basis of an ill-considered valuation.

\section{POST-LEASE EVENTS}

One of the common arguments that arises in assessing the loss is that whatever happens after the lease is determined is the basis of the valuation. Consequently, it is common to find landlords importing all manner of assumptions supported by the post-lease events. These include rents, rent-free periods, costs of works, losses of rent, service charge and rates, to name but a few. There is a powerful argument for saying that circumstances occuring after the lease expires are weighty evidence on which to base the diminution valuation. This point was considered in 'Shortlands' when it was held that events after the determination of the lease do not affect matters save insofar as they may be evidence of what was in prospect at the end of the term. Valuers should be very cautious of making an automatic assumption that this evidence is conclusive, for the following reasons:

- The new lease granted may be on wholly different terms from the lease that has expired, including the demise.

- The landlord may have had to carry out work on the property that goes beyond the repairs required by the actual lease, merely to induce the new tenant to take a lease.

Refurbishment of the building is a prime example. Simply leaving the building in repair may not be sufficient to attract a tenant in the market.

- The landlord may not have marketed the building diligently, and hence not mitigated his losses, a particularly important point when looking at rent-free periods.

- Other incentives may have been offered without which the letting may not have taken place. 
These are but a few areas in which it pays the valuers to make careful enquiries rather than make bald assumptions that what actually happened is relevant to the valuation exercise.

\section{THE ROLE OF THE VALUER}

Finally, it is worth mentioning the role of the valuer in a dilapidations claim. The valuer may be asked to fulfil any one or a combination of three roles.

In the first role, he is purely a valuer there to provide advice as to the effect, if any, of Section 18, and if so the quantum. This enables the client to formulate its property policy, likely income or expenditure stream and whether or not the prosecution or defence of a claim is worthwhile. At this point, it is worth warning that solicitors frequently ask for an Expert Witness Report from the outset. The author would resist this in the early stages because he does not yet consider himself to be an Expert Witness, but rather an expert adviser. ${ }^{13}$ From a purely technical point of view, it is also worth remembering that Expert Witnesses can only be called with the leave of the court ${ }^{14}$ and in the early stages no such consent has been given. The Guidance Note does, however, emphasise that valuers should be influenced by the considerations of an Expert Witness. ${ }^{15}$

The second role of the valuer is likely to fall in the negotiation stage after the schedule and valuation have been served and before the parties resort to litigation to resolve their differences.

Lastly, the valuer may be called upon to act as Expert Witness in litigation proceedings in which his calculations will be scrutinised in detail not only by the other side, but possibly also by the judge. Given that ultimately valuation calculations may be placed under scrutiny by the courts, it is important to get them right from the start. It must not be forgotten that any obligations as an Expert Witness, if not recognised from the outset, may come back to haunt the valuer at a later date.

Finally, do not let clients be automatically guided to go down the court route if valuations cannot be agreed. Mediation or PACT are very well suited to this type of dispute and their use can form an appropriate client recommendation.

\section{CONCLUSION}

This has been a very brief canter through this subject. Section 18 valuations are rarely straightforward. They seem to have developed a mystique about them and to be shrouded in preceived sorcery. There appears to be a shortage of experienced Section 18 valuers. Indeed, in the author's professional practice, only limited and very experienced valuers are allowed to undertake them.

\footnotetext{
Notes

Dilapidations Guidance Note, 6th Edition, 7.11.2.

2 Dilapidations Protocol 10.2.1-10.3.

3 Ferguson Latimer \& another Carney [2006] 50 EG 86.

4 Dilapidations Guidance Note, 6th Edition, 7.11.2-7.11.6.

5 Dilapidations Guidance Note, 6th Edition, 4.8, 7.8.2 \& 7.11.4.

6 Rating (Empty Properties) Act 2007.

7 Business Rates Information Letter 9/07, http:/www.local.communities.gov.uk/busrates/htm.

8 Dilapidations Guidance Note, 6th Edition, 7.6.8.

9 Ferguson Latimer and Another v Carney [2006] 50 EG 86.
} 
${ }^{10}$ Dilapidations Protocol 10.1.3.

${ }^{11}$ Shortlands Investments Ltd v Cargill plc [1995] 1EG 51.

${ }^{12}$ Lynedown Ltd v Vitamol Ltd [2007] 47 EG 170.

${ }^{13}$ Dilapidations Guidance Note, 6th Edition, 2.2.5.

${ }^{14}$ Civil Procedure Rules Part 35.4.

${ }^{15}$ Dilapidations Guidance Note, 6th Edition, 2.2.5. 